Research Article

\title{
VIKOR Method for Evaluating the Management Quality of Teacher Education with Probabilistic Hesitant Fuzzy Information
}

\author{
Li Zhiqi \\ College of Education, Shaanxi Ankang University, Ankang 725000, Shaanxi, China \\ Correspondence should be addressed to Li Zhiqi; lizhiqi@aku.edu.cn
}

Received 26 August 2021; Revised 11 October 2021; Accepted 1 December 2021; Published 15 December 2021

Academic Editor: Zeshui Xu

Copyright (C $2021 \mathrm{Li}$ Zhiqi. This is an open access article distributed under the Creative Commons Attribution License, which permits unrestricted use, distribution, and reproduction in any medium, provided the original work is properly cited.

\begin{abstract}
In the era of enhancing the quality of education, teacher quality, as the core factor affecting the quality of education, has received unprecedented attention in the field of education. The monitoring on teacher quality is the basis of fully understanding and effectively improving the quality of teachers in compulsory education within the county. Comprehensive and systematic study on teacher quality control in compulsory education within the county is the key to improve the teacher quality of it as well as improve and complement research in related fields. And in stark contrast to the importance of the problem, there is no in-depth and systematic result on the monitoring on teacher quality within the county which becomes a matter of concern in current research in the field of education issues. And the management quality evaluation of teacher education is frequently viewed as the multiple attribute decision-making (MADM) issue. An extended VIKOR model is established to provide a new approach to solve the management quality evaluation of teacher education. The VIKOR method with probabilistic hesitant fuzzy information is applied to rank the optional solutions. Lastly, a numerical example about management quality evaluation of teacher education is illustrated to test the newly proposed method's practicability.
\end{abstract}

\section{Introduction}

In 1965, Zadeh [1] firstly defined novel fuzzy sets (FSs) to cope with information in the fuzzy new domain [2-5]. To extend the FSs, the intuitionistic fuzzy sets (IFSs) [6] were also defined. Subsequently, FSs and its related extension knowledges are exploited into the more and more decision analysis domains [7-10]. Su et al. [11] proposed the interactive method for dynamic IF-MAGDM. Arya and Yadav [12] defined the intuitionistic fuzzy super-efficiency slackbased measure. Tian et al. [13] studied the partial derivative and complete differential of binary IF-mathematical functions. Garg [14] proposed the improved cosine similarity measure for IFSs. Tan [15] constructed the Choquet integralbased TOPSIS method for IF-MADM. Zhao et al. [16] defined the interactive intuitionistic fuzzy algorithms for multilevel programming problems. Li [17] built the GOWA operator to MADM using IFSs. Buyukozkan et al. [18] selected the transportation schemes with integrated intuitionistic fuzzy Choquet integral method. Joshi et al. [19] defined the Jensen-alpha-norm dissimilarity measure for IFSs. De and Sana [20] defined the $(p, q, r, l)$ method for random demand with Bonferroni mean under IFSs. Li et al. [21] defined the time-preference and VIKOR-based dynamic method for IF-MADM. Niroomand [22] defined the multiobjective-based direct solution method for linear programming along with intuitionistic fuzzy parameters. Zhao et al. [23] perfected TODIM for IF-MAGDM on the strength of cumulative prospect theory. Yu et al. [24] defined the derivatives and differentials for multiplicative IFSs. Yu [25] defined the generalized prioritized geometric operators under IFSs. Wu and Zhang [26] built the IF-MADM based on weighted entropy. Verma and Sharma [27] defined the measure of inaccuracy IF-MADM. Iakovidis and Papageorgiou [28] defined the cognitive maps for medical decision-making under IFSs. Zhang et al. [29] built the GRA method based on cumulative prospect theory for intuitionistic fuzzy MAGDM. Zhao et al. [30] built the intuitionistic fuzzy MABAC method based on cumulative prospect theory. 
The VlseKriterijumska Optimizacija I Kompromisno Resenje (VIKOR) [31-34] has been used to solve the GSS problems with different fuzzy information. Pamucar et al. [35] presented the original pairwise-CODAS method for MCDM. Roy et al. [36] established the CODAS method for MCDM issues with IVIFSs. Lan et al. [37] defined the interval-valued bipolar uncertain linguistic CODAS method. Wei et al. [38] defined the probabilistic uncertain linguistic CODAS method. He et al. [39] defined the CODAS procedures for 2-tuple linguistic Pythagorean fuzzy MAGDM. Lei et al. [40] built the probabilistic double hierarchy linguistic CODAS method. And the concept of fuzziness was first introduced by Zadeh [1], and then, it was expanded to many fields such as the decision and control. The intuitionistic fuzzy set (IFS) [41], hesitant fuzzy set (HFS) [42], interval-valued intuitionistic fuzzy set (IVIFS) [43], and so on are the expansion of the fuzzy sets. Then, Opricovic and Tzeng [44] defined the probabilistic hesitant fuzzy sets (PHFs). Until now, there are no studies for the VIKOR method under probabilistic hesitant fuzzy (PHF) environment. Thus, we extend the VIKOR method to probabilistic hesitant fuzzy (PHF) environment to deal with the flexible and complicated decision-making circumstance. Though the PHF-VIKOR model has been structured by Krishankumar et al. [45], we have some details changed in this paper to get more accruable selection. The following is the innovation of this paper: (1) a novel PHF-VIKOR method is proposed; (2) the extended VIKOR method is developed in the probabilistic hesitant fuzzy environment; (3) the normalization process of the original data has adapted the latest method to verify the precision; (4) the sensitivity analysis and comparison analysis is given with other existing models.

The whole thread of the article is as follows. Section 2 gives a simple introduction of the PHF concept. Section 3 structures the model of VIKOR, and Section 4 illustrates an example for management quality evaluation of teacher education to prove the practicability of this new method. Section 5 gives a conclusion.

\section{Preliminary Knowledge}

Definition 1 (see [46]). Let $e$ be a discourse set, and PHFS on $E$ is in terms of a function that when applied to $E$ whose value range is in $[0,1]$ and the probabilistic hesitant fuzzy element (PHFE) is denoted as $k_{e}\left(j_{e}^{a}\right)$ is as follows:

$$
K_{e}=\left\{k_{e}\left(f_{e}^{a} \mid j_{e}^{a}\right) \mid f_{e}^{a}, j_{e}^{a}\right\},
$$

where $f_{e}^{a} \in R, 0 \leq f_{e}^{a} \leq 1, a=1,2, \ldots, \# f$, and $\# f$ is the value of the elements, $f_{e}^{a}$ is the possible membership degrees, and $j_{e}^{a}$ is the probability of the corresponding element, $\sum_{a=1}^{\# f} f_{e}^{a}=1$. We adapt a new normalization approach which is introduced by Li et al. [47] for the reason that this new normalization process breaks the limitation when processing multiplication of the sets with different probabilities.

Definition 2 (see [47]). Let $k\left(f_{i} \mid j_{i}\right)=\left\{f^{i}\left(j^{i}\right)\right\}$, $k_{1}\left(f_{a} \mid j_{a}\right)=\left\{f_{1}^{a}\left(j_{1}^{a}\right)\right\}$, and $k_{2}\left(f_{b} \mid j_{b}\right)=\left\{f_{2}^{a}\left(j_{2}^{a}\right)\right\}$ be three
PHFEs, $\quad i=1,2, \ldots, \# f, \quad a=1,2, \ldots, \# f_{1}, \quad$ and $b=1,2, \ldots, \# f_{2}$.

Step 1: determine the first element of normalized PHFEs. If $j_{1}^{1}<j_{2}^{1}$, then $f_{1}^{1}\left(j_{1}^{1}\right)=f_{1}^{1}\left(j_{1}^{1}\right)$ and $f_{2}^{1}\left(j_{2}^{1}\right)=f_{2}^{1}\left(j_{2}^{1}\right) ; \quad$ otherwise, $f_{1}^{1}\left(j_{1}^{1}\right)=f_{1}^{1}\left(j_{2}^{1}\right)$ and $f_{2}^{1}\left(j_{2}^{1}\right)=f_{2}^{1}\left(j_{2}^{1}\right)$.

Step 2: determine the second element of standardized PHFEs. If $j_{1}^{1}<j_{2}^{1}$ and $j_{2}^{1}-j_{1}^{1} \leq j_{1}^{2}$, then $f_{1}^{2}\left(j_{1}^{2}\right)=f_{1}^{2}\left(j_{2}^{1}-j_{1}^{1}\right)$ and $f_{2}^{2}\left(j_{2}^{2}\right)=f_{2}^{1}\left(j_{2}^{1}-j_{1}^{1}\right)$. If $j_{1}^{1}<j_{2}^{1}$ and $j_{2}^{1}-j_{1}^{1}>j_{1}^{2}$, then $f_{1}^{2}\left(j_{1}^{2}\right)=f_{1}^{2}\left(j_{1}^{2}\right)$ and $f_{2}^{2}\left(j_{2}^{2}\right)=f_{2}^{1}\left(j_{1}^{2}\right)$. If $j_{1}^{1} \geq j_{2}^{1}$ and $j_{1}^{1}-j_{2}^{1} \leq j_{2}^{2}$, then $f_{1}^{2}\left(j_{1}^{2}\right)=f_{1}^{1}\left(j_{1}^{1}-j_{2}^{1}\right)$ and $f_{2}^{2}\left(j_{2}^{2}\right)=f_{2}^{2}\left(j_{1}^{1}-j_{2}^{1}\right)$. If $j_{1}^{1} \geq j_{2}^{1}$ and $j_{1}^{1}-j_{2}^{1}>j_{2}^{2}$, then $f_{1}^{2}\left(j_{1}^{2}\right)=f_{1}^{1}\left(j_{2}^{2}\right)$ and $f_{2}^{2}\left(j_{2}^{2}\right)=f_{2}^{2}\left(j_{2}^{2}\right)$.

Step 3: determine the third element of standardized PHFEs. If $j_{1}^{1} \geq j_{2}^{1}, j_{1}^{1}-j_{2}^{1} \leq j_{2}^{2}$ and $j_{2}^{1} \leq j_{2}^{2}-j_{1}^{1}+j_{2}^{1}$, then $f_{1}^{3}\left(j_{1}^{3}\right)=f_{1}^{2}\left(j_{1}^{2}\right)$ and $f_{2}^{3}\left(j_{2}^{3}\right)=f_{2}^{2}\left(j_{1}^{2}\right)$. If $j_{1}^{1} \geq j_{2}^{1}, j_{1}^{1}-$ $j_{2}^{1} \leq j_{2}^{2}$ and $j_{2}^{1}>j_{2}^{2}-j_{1}^{1}+j_{2}^{1}$, then $f_{1}^{3}\left(j_{1}^{3}\right)=f_{1}^{2}\left(j_{2}^{2}+j_{2}^{1}-\right.$ $\left.j_{1}^{1}\right)$ and $f_{2}^{3}\left(j_{2}^{3}\right)=f_{2}^{2}\left(j_{2}^{2}+j_{2}^{1}-j_{1}^{1}\right)$.

From the above steps, $j_{1}^{1}+j_{1}^{2}+\cdots j_{1}^{\# f_{1}}=1$ and $j_{2}^{1}+j_{2}^{2}+\cdots j_{2}^{\# f_{2}}=1, \# f_{1}=\# f_{2}$.

Definition 3 (see [46]). The score function is calculated by

$$
s(\bar{k}(\bar{j}))=\sum_{i=1}^{\# f} \bar{f}^{i-i}
$$

where $\bar{f}^{i}$ shows the $i$ th largest elements of PHFE and $\bar{j}^{i}$ is the probability of the $i$ th largest membership degree.

Definition 4 (see [48]). Compare $\bar{k}_{1}\left(\bar{j}_{1}\right)=\left\{\bar{f}_{1}^{a}\left(\bar{j}_{1}^{a}\right)\right\}$ and $\bar{k}_{2}\left(\bar{j}_{2}\right)=\left\{\bar{f}_{2}^{b}\left(\bar{j}_{2}^{b}\right)\right\}$ by the following laws:

(1) $\bar{k}_{1}\left(\bar{j}_{1}\right)>\bar{f}_{2}\left(\bar{j}_{2}\right)$ if $s\left(\bar{k}_{1}\left(\bar{j}_{1}\right)\right)>s\left(\bar{k}_{2}\left(\bar{j}_{2}\right)\right)$

(2) $\bar{k}_{1}\left(\bar{j}_{1}\right)>\bar{f}_{2}\left(\bar{j}_{2}\right) \quad$ if $\quad s\left(\bar{k}_{1}\left(\bar{j}_{1}\right)\right)>s\left(\bar{k}_{2}\left(\bar{j}_{2}\right)\right) \quad$ and $d\left(\bar{k}_{1}\left(\bar{j}_{1}\right)\right)>d\left(\bar{k}_{2}\left(\bar{j}_{2}\right)\right)$

(3) $\bar{k}_{1}\left(\bar{j}_{1}\right)=\bar{f}_{2}\left(\bar{j}_{2}\right) \quad$ if $s\left(\bar{k}_{1}\left(\bar{j}_{1}\right)\right)=s\left(\bar{k}_{2}\left(\bar{j}_{2}\right)\right) \quad$ and $d\left(\bar{k}_{1}\left(\bar{j}_{1}\right)\right)=d\left(\bar{k}_{2}\left(\bar{j}_{2}\right)\right)$

(4) $\bar{k}_{1}\left(\bar{j}_{1}\right)<\bar{f}_{2}\left(\bar{j}_{2}\right) \quad$ if $\quad s\left(\bar{k}_{1}\left(\bar{j}_{1}\right)\right)=s\left(\bar{k}_{2}\left(\bar{j}_{2}\right)\right) \quad$ and $d\left(\bar{k}_{1}\left(\bar{j}_{1}\right)\right)>d\left(\bar{k}_{2}\left(\bar{j}_{2}\right)\right)$

Definition $\quad{ }^{5}$ (see $\left.\quad[48]\right) \cdot \bar{k}_{1}\left(\bar{j}_{1}\right)=\left\{\bar{f}_{1}^{a}\left(\bar{j}_{1}^{a}\right)\right\} \quad$ and $\bar{k}_{2}\left(\bar{j}_{2}\right)=\left\{\bar{f}_{2}^{b}\left(\bar{j}_{2}^{b}\right)\right\} \quad$ are normalized PHFEs, where $\# f_{1}=\# f_{2}=\# f$ and $j_{1}^{a}=j_{2}^{b}=j^{i}$. The Lance distance between them is arranged as

$$
d\left(\bar{k}_{1}\left(\bar{j}_{1}\right), \bar{k}_{2}\left(\bar{j}_{2}\right)\right)=\frac{1}{\# f} \sum_{a=b=1}^{\# f} \frac{\left|\bar{f}_{1}^{a-a} j_{1}^{a}-\bar{f}_{2}^{b-b} j_{2}\right|}{\bar{f}_{1}^{a-a} j_{1}^{a}+\bar{f}_{2}^{b} \bar{j}_{2}^{b}} .
$$

Definition 6 (see [47]). The algorithms of two normalized PHFEs $\bar{k}_{1}\left(\bar{j}_{1}\right)=\left\{\bar{f}_{1}^{a}\left(\bar{j}_{1}^{a}\right)\right\} \quad$ and $\bar{k}_{2}\left(\bar{j}_{2}\right)=\left\{\bar{f}_{2}^{b}\left(\bar{j}_{2}\right)\right\} \quad$ are as
follows: 
(1) $\bar{k}_{1}\left(\bar{j}_{1}\right) \oplus \bar{k}_{2}\left(\bar{j}_{2}\right)=\cup_{a=1, \ldots, \# \bar{f}_{1}, b=1, \ldots, \bar{f}_{2}}\left\{\left(\bar{f}_{1}^{a}+\bar{f}_{2}^{b}-\bar{f}_{1}^{a} \bar{f}_{2}^{b}\right)\left(\bar{j}^{i}\right)\right\}$,

(2) $\bar{k}_{1}\left(\bar{j}_{1}\right) \otimes \bar{k}_{2}\left(\bar{j}_{2}\right)=\cup_{a=1, \ldots, \# \bar{f}_{1}, b=1, \ldots, \# \bar{f}_{2}}\left\{\bar{f}_{1}^{a} \bar{f}_{2}^{b}\left(\bar{j}^{i}\right)\right\}$.

Definition 7 (see [49]). Let $\bar{h}_{c}(c=1,2, \ldots, l)$ be a fixed collection, and the PHF weighted averaging (PHFWA) operator is obtained by

$$
\begin{aligned}
& \operatorname{PHFWA}\left(\bar{h}_{1}\left(\bar{j}_{1}\right), \bar{h}_{2}\left(\bar{j}_{2}\right), \ldots, \bar{h}_{l}\left(\bar{j}_{l}\right)\right)=\underset{c=1}{\oplus}\left(\bar{h}_{c} v_{c}\right) \\
& =\underset{\bar{f}_{1} \in \bar{h}_{1}, \bar{f}_{2} \in \bar{h}_{2}, \ldots, \bar{f}_{l} \in \bar{h}_{l}}{U}\left\{1-\prod_{c=1}^{l}\left(1-f_{c}\right)^{v_{c}}\left(\bar{j}^{i}\right)\right\},
\end{aligned}
$$

where $v_{c}=\left(v_{1}, v_{2}, \ldots, v_{l}\right)$ is the weight of $v_{c}$ and $\sum_{c=1}^{l} v_{c}=1$, $v_{c} \in[0,1]$.
Definition 8 (see [49]). The equation of PHF weighted geometric (PHFWG) operator is shown as follows:

$$
\begin{aligned}
& \operatorname{PHFWG}\left(\bar{h}_{1}\left(\bar{j}_{1}\right), \bar{h}_{2}\left(\bar{j}_{2}\right), \ldots, \bar{h}_{l}\left(\bar{j}_{l}\right)\right)=\underset{c=1}{\stackrel{\oplus}{\oplus}}\left(\bar{h}_{c}\right)^{v_{c}} \\
= & \underset{\bar{f}_{1} \in \bar{h}_{1}, \bar{f}_{2} \in \bar{h}_{2}, \ldots, \bar{f}_{l} \in \bar{h}_{l}}{\cup}\left\{\prod_{c=1}^{l}\left(f_{c}\right)^{v_{c}}\left(\bar{j}^{i}\right)\right\} .
\end{aligned}
$$

\section{PHF-VIKOR Method for MAGDM}

The MAGDM decision matrix is $K^{c}=\left[k_{e r}^{c}\left(j_{e r}\right)\right]_{m \times n}$, and the optional alternatives is defined as $W_{e}=\left\{W_{1}, W_{2}, \ldots, W_{m}\right\}$ and the attributes are $Y_{r}=\left\{Y_{1}, Y_{2}, \ldots, Y_{n}\right\}$, and $c=\left\{c_{1}, c_{2}, \ldots, c_{l}\right\}$ is used to denote the decision makers. Furthermore, the weight of each decision maker is defined as $v_{c}$ and the weighting vector of criterions is $p_{r}$ which is unknown, $\sum_{c=1}^{l} v_{c}=1, \sum_{r=1}^{n} p_{r}=1(c=1,2, \ldots l)$ :

$$
K^{c}=\left[\begin{array}{ccccc}
k_{11}^{c} & \ldots & k_{1 r}^{c} & \cdots & k_{1 n}^{c} \\
\vdots & \ddots & \vdots & \ddots & \vdots \\
k_{e 1}^{c} & \cdots & k_{e r}^{c} & \cdots & k_{e n}^{c} \\
\vdots & \ddots & \vdots & \ddots & \vdots \\
k_{m 1}^{c} & \cdots & k_{m r}^{c} & \cdots & k_{m n}^{c}
\end{array}\right]_{m \times n} ; e=1, \ldots, m, r=1, \ldots, n, c=1, \ldots, l .
$$

Then, the PHF-VIKOR method is used to deal with MAGDM with PHFNs.

Step 1: obtain the standardized decision matrices:

$$
\begin{cases}\bar{k}_{e r}\left(\bar{j}_{e r}\right)=\left\{f_{e r}\left(\bar{j}_{e r}\right)\right\}, & \text { if the attribute is the positive attribute, } \\ \bar{k}_{e r}\left(\bar{j}_{e r}\right)=\left\{\left(1-f_{e r}\right)\left(\bar{j}_{e r}\right)\right\}, & \text { if the attribute is the negative attribute. }\end{cases}
$$

Then, we obtain the normalized data according to the introduction in Definition 2.

Step 2: integrate the group matrix into a matrix $\widehat{k}_{e r}\left(\widehat{j}_{e r}\right)=\left\{\widehat{f}_{e r}\left(\widehat{j}_{e r}\right)\right]_{m \times n}$ using

$$
\begin{aligned}
& \operatorname{PHFWA}\left(\bar{k}_{e r}^{1}, \bar{k}_{e r}^{2}, \ldots, \bar{k}_{e r}^{l}\right)=\underset{c=1}{\oplus}\left(\bar{k}_{e r}^{c} v_{c}\right) \\
& =\underset{\bar{f}_{e r}^{1} \in \bar{k}_{e r}^{1}, \bar{f}_{e r}^{2} \bar{k}_{e r}^{2}, \ldots, \bar{f}_{e r}^{l} \bar{k}_{e r}^{l}}{U}\left\{1-\prod_{c=1}^{l}\left(1-\bar{f}_{e r}^{c}\right)^{v_{c}}(\bar{j})\right\} .
\end{aligned}
$$

Step 3: obtain the matrix of the score function of the integrated decision matrix:

$$
s\left(\widehat{k}_{e r}\left(\hat{j}_{e r}\right)\right)=\sum_{i=1}^{\# f} \widehat{f}_{e r}^{i} \hat{j}_{e r}^{i} .
$$

Step 4: acquire the criterion weights based on the information provided by DMs.
The classical entropy-weighted method is used to obtain the weights among attributes $p_{r}$. The calculation process is shown as follows:

(i) Obtain the degree of entropy by the following equation:

$$
T_{r}=-\frac{1}{\ln m} \sum_{e=1}^{m} \frac{s\left(\widehat{k}_{e r}\left(\hat{j}_{e r}\right)\right)}{\sum_{e=1}^{m} s\left(\widehat{k}_{e r}\left(\hat{j}_{e r}\right)\right)} \times \ln \left(\frac{s\left(\widehat{k}_{e r}\left(\hat{j}_{e r}\right)\right)}{\sum_{e=1}^{m} s\left(\widehat{k}_{e r}\left(\hat{j}_{e r}\right)\right)}\right) .
$$

(ii) Calculate the entropy weight $p_{r}$ :

$$
p_{r}=\frac{1-T_{r}}{\sum_{r=1}^{n}\left(1-T_{r}\right)} \text {. }
$$

Step 5: determine the $\widehat{k}^{*}$ and $\widehat{k}^{-}$indexes by the following laws: 


$$
\left\{\begin{array}{l}
\widehat{k}_{r}^{*}=\max _{\mathrm{e}} \widehat{k}_{e r}, \\
\widehat{k}_{r}^{-}=\min _{\mathrm{e}} \widehat{k}_{e r} .
\end{array}\right.
$$

Step 6: calculate the $S$ and $R$ indexes by the following equations:

$$
\begin{aligned}
& S_{e}=\sum_{r=1}^{n} p_{r} \frac{\left(\widehat{k}_{r}^{*}-\widehat{k}_{e r}\right)}{\left(\widehat{k}_{r}^{*}-\widehat{k}_{r}^{-}\right)} \\
& R_{e}=\max _{r}\left[p_{r} \frac{\left(\widehat{k}_{r}^{*}-\widehat{k}_{e r}\right)}{\left(\widehat{k}_{r}^{*}-\widehat{k}_{r}^{-}\right)}\right] .
\end{aligned}
$$

Step 7: compute out the VIKOR index according to the previous step:

$$
Q_{e}=\delta \times\left[\frac{S_{e}-S^{-}}{S^{*}-S^{-}}\right]+(1-\delta) \times\left[\frac{R_{e}-R^{-}}{R^{*}-R^{-}}\right],
$$

where $\delta$ denotes the strategic weight whose value is always defined to 0.5 [44], $S^{*}=\max _{e} S_{e}, S^{-}=\min _{e} S_{e}$ $R^{*}=\max _{e} R_{e}$, and $R^{-}=\min _{e} R_{e}$.

Step 8: get the final ranking of the solutions.

The final ranking results is determined by three parameters $\left(Q_{e}, R_{e}\right.$, and $\left.S_{e}\right)$. The value of these parameters means the smaller it is, the better the alternative is.

\section{Case Study}

The education plan is teacher-oriented. Excellent teachers can create excellent education. Education to teachers is the base of educational career which plays an important role in laying foundation and leading the way. Education to teachers takes up the significant position in educational career of different countries and promoting the quality of the public. Our country attaches great importance to the education to teachers and the quality improving of teachers has been put on the top of country develop strategy. Education to teachers in China has a long history and higher level. It experiences the process from nothing to everything, from disorder to making specific rules, from lower lever to higher level. The system of education to teachers has cultivated groups of qualified teachers for elementary and middle school to meet the demands of social politics and economy as well as scientific development, which contributes to the improvement of civil quality and economic development as well as the science and techniques. Research on the reform and develop history of Chinese education to teachers from the aspect of quality assurance not only contributes to deeply understanding the reform of education to teachers and quality assurance and enriching the research on American educational history but also has a significant influence in China, establishing and improving the teachers' education institutions, reconstructing the policy of education to teachers, and improving the quality of teachers. A point in case about the management quality of teacher education with PHFNs would be utilized to illustrate the above methods. We shall give 5 possible college schools $H_{i}(i=1,2,3,4,5)$ to choose. The experts select four attributes to evaluate the management quality of teacher education of these college schools: (1) $J_{1}$ represents the environment of teaching and studying; (2) $J_{2}$ means curriculum design and target; (3) $J_{3}$ represents the teaching practice; (4) $J_{4}$ means the student satisfaction. Several college schools shall be depicted with PHFNs by the three DMs (expert weighting is $v_{c}=\{0.3,0.3,0.4\}$ ) on the strength of 4 criterions; the PHFN decision matrix is depicted in Tables 1-3.

Then, the PHF-VIKOR method is used to deal with management quality evaluation of teacher education with PHFNs.

Step 1: obtain the normalized matrices (see Tables 4-6). Step 2: obtain the integrated decision matrix $\widehat{k}_{e r}\left(\widehat{j}_{e r}\right)=$ $\left\{\widehat{f}_{e r}\left(\widehat{j}_{e r}\right)\right]_{m \times n}$ (see Table 7$)$.

Step 3: build the score function of the integrated decision matrix (see Table 8).

Step 4: using the entropy method, we compute out the weighting vector with the decision-making information $p_{r}=\{0.269,0.279,0.257,0.195\}$.

Step 5: determine the $\widehat{k}^{*}$ and $\widehat{k}^{-}$indexes:

$$
\begin{aligned}
& \widehat{k}^{*}=\{0.589,0.633,0.533,0.521\}, \\
& \widehat{k}^{-}=\{0.356,0.381,0.316,0.350\} .
\end{aligned}
$$

Step 6: calculate the $S$ and $R$ indexes:

$$
\begin{aligned}
& S_{e}=\{0.914,0.842,0.790,0\}, \\
& R_{e}=\{0.257,0.269,0.279,0\} .
\end{aligned}
$$

Step 7: compute out the VIKOR index according to the previous step:

$$
Q_{e}=\{0.960,0.942,0.932,0\}
$$

Step 8: get the final ranking of the solutions: 
TABLE 1: Decision matrix $c_{1}$ given by the first DM.

\begin{tabular}{lcr}
\hline Alternative & $Y_{1}$ & $Y_{2}$ \\
$W_{1}$ & $\{0.6(0.1), 0.5(0.2), 0.3(0.7)\}$ & $\{0.3(0.5), 0.5(0.5)\}$ \\
$W_{2}$ & $\{0.4(0.3), 0.5(0.4), 0.2(0.3)\}$ & $\{0.5(1)\}$ \\
$W_{3}$ & $\{0.7(0.4), 0.4(0.3), 0.1(0.3)\}$ & $\{0.4(0.7), 0.7(0.3)\}$ \\
$W_{4}$ & $\{0.6(0.7), 0.5(0.3)\}$ & $\{0.5(0.3), 0.7(0.5), 0.6(0.2)\}$ \\
\hline Alternative & $Y_{1}$ & $\{0.3(0.5), 0.6(0.2), 0.4(0.3)\}$ \\
$W_{1}$ & $\{0.3(0.6), 0.2(0.3), 0.4(0.1)\}$ & $\{0.4(0.2), 0.5(0.3), 0.3(0.5)\}$ \\
$W_{2}$ & $\{0.4(0.6), 0.3(0.3), 0.5(0.1)\}$ & $\{0.5(0.25), 0.3(0.5)\}$ \\
$W_{3}$ & $\{0.4(0.5), 0.2(0.2), 0.3(0.3)\}$ & $\{0.5(0.6), 0.4(0.2), 0.7(0.2)\}$ \\
$W_{4}$ & $\{0.5(1)\}$ &
\end{tabular}

TABLE 2: Decision matrix $c_{2}$ given by the second DM.

\begin{tabular}{lcr}
\hline Alternative & $Y_{1}$ & $Y_{2}$ \\
$W_{1}$ & $\{0.5(0.4), 0.4(0.5), 0.7(0.1)\}$ & $\{0.4(0.8), 0.5(0.2)\}$ \\
$W_{2}$ & $\{0.4(0.7), 0.3(0.3)\}$ & $\{0.3(0.4), 0.4(0.2), 0.6(0.4)\}$ \\
$W_{3}$ & $\{0.5(1)\}$ & $\{0.2(0.5), 0.4(0.5)\}$ \\
$W_{4}$ & $\{0.8(0.6), 0.5(0.3), 0.7(0.1)\}$ & $\left\{\begin{array}{l}2 \\
\text { Alternative }\end{array}\right.$ \\
$W_{1}$ & $\{0.4(1)\}$ & $\{0.5), 0.4(0.1), 0.5(0.3)\}$ \\
$W_{2}$ & $\{0.3(0.3), 0.5(0.2), 0.4(0.5)\}$ & $\{0.4(0.3), 0.6(0.1), 0.2(0.6)\}$ \\
$W_{3}$ & $\{0.4(0.6), 0.3(0.4)\}$ & $\{0.3(0.5), 0.2(0.2), 0.4(0.3)\}$ \\
$W_{4}$ & $\{0.5(0.7), 0.4(0.3)\}$ & $\{0.4(0.3), 0.5(0.5), 0.6(0.2)\}$ \\
\hline
\end{tabular}

TABLE 3: Decision matrix $c_{3}$ given by the third DM.

\begin{tabular}{lcr}
\hline Alternative & $Y_{1}$ & $Y_{2}$ \\
\hline$W_{1}$ & $\{0.1(0.4), 0.6(0.3), 0.4(0.3)\}$ & $\{0.3(0.5), 0.6(0.2), 0.5(0.3)\}$ \\
$W_{2}$ & $\{0.2(0.5), 0.4(0.3), 0.5(0.2)\}$ & $\{0.4(0.6), 0.2(0.2) 0.5(0.2)\}$ \\
$W_{3}$ & $\{0.5(0.3), 0.4(0.7)\}$ & $\{0.2(0.4), 0.4(0.6)\}$ \\
$W_{4}$ & $\{0.6(0.4), 0.5(0.6)\}$ & $\{0.5(0.4), 0.3(0.1), 0.8(0.5)\}$ \\
\hline Alternative & $Y_{1}$ & $\{0.3(0.5), 0.2(0.3), 0.4(0.2)\}$ \\
$W_{1}$ & $\{0.3(0.4), 0.2(0.5), 0.5(0.1)\}$ & $\{0.3(0.2), 0.4(0.5), 0.5(0.3)\}$ \\
$W_{2}$ & $\{0.4(0.6), 0.3(0.2), 0.2(0.2)\}$ & $\{0.4(0.7), 0.2(0.3)\}$ \\
$W_{3}$ & $\{0.7(0.3), 0.5(0.4), 0.2(0.3)\}$ & $\{0.4(0.2), 0.5(0.3), 0.6(0.5)\}$ \\
$W_{4}$ & $\{0.6(0.3), 0.5(0.4), 0.7(0.3)\}$ &
\end{tabular}

TABle 4: The standardized decision matrix by the first DM.

\begin{tabular}{lcc}
\hline Alternative & $M_{1}$ & $M_{2}$ \\
$W_{1}$ & $\{0.6(0.1), 0.5(0.2), 0.3(0.2), 0.3(0.2), 0.3(0.3)\}$ & $\{0.3(0.1), 0.3(0.2), 0.3(0.2), 0.5(0.2), 0.5(0.3)\}$ \\
$W_{2}$ & $\{0.4(0.1), 0.4(0.2), 0.5(0.2), 0.5(0.2), 0.3(0.3)\}$ & $\{0.5(0.1), 0.5(0.2), 0.5(0.2), 0.5(0.2), 0.5(0.3)\}$ \\
$W_{3}$ & $\{0.4(0.1), 0.4(0.2), 0.7(0.2), 0.7(0.2), 0.1(0.3)\}$ & $\{0.7(0.1), 0.7(0.2), 0.4(0.2), 0.4(0.2), 0.4(0.3)\}$ \\
$W_{4}$ & $\{0.5(0.1), 0.5(0.2), 0.6(0.2), 0.6(0.2), 0.6(0.3)\}$ & $\{0.5(0.1), 0.5(0.2), 0.6(0.2), 0.7(0.2), 0.7(0.3)\}$ \\
\hline Alternative & $M_{3}$ & $M_{4}$ \\
$W_{1}$ & $\{0.4(0.1), 0.3(0.2), 0.3(0.2), 0.3(0.2), 0.2(0.3)\}$ & $\{0.4(0.1), 0.4(0.2), 0.6(0.2), 0.3(0.1), 0.3(0.3)\}$ \\
$W_{2}$ & $\{0.5(0.1), 0.4(0.2), 0.4(0.2), 0.4(0.2), 0.3(0.3)\}$ & $\{0.5(0.1), 0.5(0.2), 0.4(0.2), 0.3(0.1), 0.3(0.3)\}$ \\
$W_{3}$ & $\{0.3(0.1), 0.3(0.2), 0.2(0.2), 0.4(0.2), 0.4(0.3)\}$ & $\{0.5(0.1), 0.5(0.2), 0.5(0.2), 0.3(0.1), 0.3(0.3)\}$ \\
$W_{4}$ & $\{0.5(0.1), 0.5(0.2), 0.5(0.2), 0.5(0.2), 0.5(0.3)\}$ & $\{0.5(0.1), 0.4(0.2), 0.7(0.2), 0.5(0.1), 0.5(0.3)\}$ \\
\hline
\end{tabular}

TABle 5: The standardized decision matrix by the second DM.

\begin{tabular}{lcc}
\hline Alternative & $M_{1}$ & $M_{2}$ \\
$W_{1}$ & $\{0.7(0.1), 0.4(0.2), 0.5(0.2), 0.5(0.2), 0.4(0.3)\}$ & $\{0.4(0.1), 0.5(0.2), 0.4(0.2), 0.4(0.2), 0.4(0.3)\}$ \\
$W_{2}$ & $\{0.3(0.1), 0.3(0.2), 0.4(0.2), 0.4(0.2), 0.4(0.3)\}$ & $\{0.3(0.1), 0.4(0.2), 0.6(0.2), 0.6(0.2), 0.3(0.3)\}$ \\
$W_{3}$ & $\{0.5(0.1), 0.5(0.2), 0.5(0.2), 0.5(0.2), 0.5(0.3)\}$ & $\{0.2(0.1), 0.2(0.2), 0.2(0.2), 0.4(0.2), 0.4(0.3)\}$ \\
$W_{4}$ & $\{0.7(0.1), 0.8(0.2), 0.8(0.2), 0.8(0.2), 0.5(0.3)\}$ & $\{0.4(0.1), 0.7(0.2), 0.7(0.2), 0.7(0.2), 0.5(0.3)\}$ \\
\hline Alternative & $M_{3}$ & $M_{4}$ \\
$W_{1}$ & $\{0.4(0.1), 0.4(0.2), 0.4(0.2), 0.4(0.2), 0.4(0.3)\}$ & $\{0.5(0.1), 0.5(0.2), 0.6(0.2), 0.2(0.2), 0.2(0.3)\}$ \\
$W_{2}$ & $\{0.3(0.1), 0.3(0.2), 0.5(0.2), 0.4(0.2), 0.4(0.3)\}$ & $\{0.6(0.1), 0.2(0.2), 0.2(0.2), 0.2(0.2), 0.4(0.3)\}$ \\
$W_{3}$ & $\{0.4(0.1), 0.3(0.2), 0.3(0.2), 0.4(0.2), 0.4(0.3)\}$ & $\{0.4(0.1), 0.4(0.2), 0.3(0.2), 0.3(0.2), 0.3(0.3)\}$ \\
$W_{4}$ & $\{0.4(0.1), 0.4(0.2), 0.5(0.2), 0.5(0.2), 0.5(0.3)\}$ & $\{0.4(0.1), 0.4(0.2), 0.6(0.2), 0.5(0.2), 0.5(0.3)\}$ \\
\hline
\end{tabular}


TABLE 6: The standardized decision matrix by the third DM.

\begin{tabular}{lcc}
\hline Alternative & $M_{1}$ & $M_{2}$ \\
$W_{1}$ & $\{0.6(0.1), 0.6(0.2), 0.1(0.2), 0.1(0.2), 0.4(0.3)\}$ & $\{0.5(0.1), 0.5(0.2), 0.6(0.2), 0.3(0.2), 0.3(0.3)\}$ \\
$W_{2}$ & $\{0.2(0.1), 0.2(0.2), 0.2(0.2), 0.5(0.2), 0.4(0.3)\}$ & $\{0.4(0.1), 0.2(0.2), 0.5(0.2), 0.4(0.2), 0.4(0.3)\}$ \\
$W_{3}$ & $\{0.5(0.1), 0.5(0.2), 0.4(0.2), 0.4(0.2), 0.4(0.3)\}$ & $\{0.4(0.1), 0.2(0.2), 0.2(0.2), 0.4(0.2), 0.4(0.3)\}$ \\
$W_{4}$ & $\{0.5(0.1), 0.6(0.2), 0.6(0.2), 0.5(0.2), 0.5(0.3)\}$ & $\{0.3(0.1), 0.5(0.2), 0.5(0.2), 0.8(0.2), 0.8(0.3)\}$ \\
\hline Alternative & $M_{3}$ & $M_{4}$ \\
$W_{1}$ & $\{0.5(0.1), 0.3(0.2), 0.3(0.2), 0.2(0.2), 0.2(0.3)\}$ & $\{0.2(0.1), 0.2(0.2), 0.4(0.2), 0.3(0.2), 0.3(0.3)\}$ \\
$W_{2}$ & $\{0.4(0.1), 0.3(0.2), 0.2(0.2), 0.4(0.2), 0.4(0.3)\}$ & $\{0.5(0.1), 0.5(0.2), 0.3(0.2), 0.4(0.2), 0.4(0.3)\}$ \\
$W_{3}$ & $\{0.7(0.1), 0.7(0.2), 0.5(0.2), 0.5(0.2), 0.2(0.3)\}$ & $\{0.2(0.1), 0.2(0.2), 0.4(0.2), 0.4(0.2), 0.4(0.3)\}$ \\
$W_{4}$ & $\{0.6(0.1), 0.6(0.2), 0.5(0.2), 0.5(0.2), 0.7(0.3)\}$ & $\{0.5(0.1), 0.5(0.2), 0.4(0.2), 0.6(0.2), 0.6(0.3)\}$ \\
\hline
\end{tabular}

TABLE 7: The integrated decision matrix.

\begin{tabular}{lccc}
\hline Alternative & $M_{1}$ & $M_{2}$ \\
$W_{1}$ & $\{0.633(0.1), 0.517(0.2), 0.300(0.2), 0.261(0.2), 0.372(0.3)\}$ & $\{0.416(0.1), 0.447(0.2), 0.466(0.2), 0.396(0.2), 0.396(0.3)\}$ \\
$W_{2}$ & $\{0.295(0.1), 0.295(0.2), 0.363(0.2), 0.416(0.2), 0.372(0.3)\}$ & $\{0.405(0.1), 0.363(0.2), 0.532(0.2), 0.497(0.2), 0.405(0.3)\}$ \\
$W_{3}$ & $\{0.472(0.1), 0.472(0.2), 0.539(0.2), 0.358(0.2), 0.358(0.3)\}$ & $\{0.469(0.1), 0.404(0.2), 0.266(0.2), 0.400(0.2), 0.400(0.3)\}$ \\
$W_{4}$ & $\{0.571(0.1), 0.653(0.2), 0.675(0.2), 0.532(0.2), 0.532(0.3)\}$ & $\{0.396(0.1), 0.571(0.2), 0.599(0.2), 0.745(0.2), 0.703(0.3)\}$ \\
\hline Alternative & $M_{3}$ & $M_{4}$ \\
$W_{1}$ & $\{0.442(0.1), 0.332(0.2), 0.332(0.2), 0.295(0.2), 0.266(0.3)\}$ & $\{0.363(0.1), 0.363(0.2), 0.530(0.2), 0.271(0.2), 0.271(0.3)\}$ \\
$W_{2}$ & $\{0.405(0.1), 0.332(0.2), 0.363(0.2), 0.400(0.2), 0.372(0.3)\}$ & $\{0.532(0.1), 0.424(0.2), 0.304(0.2), 0.315(0.2), 0.372(0.3)\}$ \\
$W_{3}$ & $\{0.524(0.1), 0.501(0.2), 0.363(0.2), 0.442(0.2), 0.327(0.3)\}$ & $\{0.363(0.1), 0.363(0.2), 0.405(0.2), 0.342(0.2), 0.342(0.3)\}$ \\
$W_{4}$ & $\{0.517(0.1), 0.517(0.2), 0.500(0.2), 0.500(0.2), 0.592(0.3)\}$ & $\{0.472(0.1), 0.442(0.2), 0.568(0.2), 0.543(0.2), 0.543(0.3)\}$ \\
\hline
\end{tabular}

TABLE 8: The score of the integrated decision matrix.

\begin{tabular}{lcccc}
\hline Alternative & $M_{1}$ & $M_{2}$ & $M_{3}$ & $M_{4}$ \\
\hline$W_{1}$ & 0.390 & 0.422 & 0.316 & 0.350 \\
$W_{2}$ & 0.356 & 0.440 & 0.371 & 0.373 \\
$W_{3}$ & 0.429 & 0.381 & 0.412 & 0.361 \\
$W_{4}$ & 0.589 & 0.633 & 0.533 & 0.521 \\
\hline
\end{tabular}

$$
\left\{\begin{array}{c}
S_{4}<S_{3}<S_{2}<S_{1} \\
R_{4}<R_{1}<R_{2}<R_{3} \\
S_{4}<S_{3}<S_{2}<S_{1}
\end{array}\right\} \text {, the final rank is } W_{4}>W_{3}>W_{2}>W_{1} .
$$

\section{Conclusions}

In this study, we propose a new PHF-VIKOR model for management quality evaluation of teacher education with probabilistic hesitant fuzzy information. In this method, the decision-making information was provided by DMs in probabilistic hesitant fuzzy environment. A novel VIKOR model was extended in the PHF circumstance for management quality evaluation of teacher education. Finally, we apply this model in a practical example and test the feasibility. In the future, we firmly believe that the PHF-VIKOR method will be applied in the more fields. Meanwhile, the integration of other classical method with more complex and uncertain information also needs more attention [50-52]. We are supposed to consider the attributes of actual situation when solving the management quality evaluation of teacher education.

\section{Data Availability}

The data used to support the findings of this study are included in the article.

\section{Conflicts of Interest}

The authors declare that they have no conflicts of interest.

\section{Acknowledgments}

This work was supported by the provincial Education Planning Office in 2018 (project no. sgh18h385).

\section{References}

[1] L. A. Zadeh, "Fuzzy sets," Information and Control, vol. 8, no. 3, pp. 338-353, 1965.

[2] H. Garg and K. Kumar, "Group decision making approach based on possibility degree measures and the linguistic intuitionistic fuzzy aggregation operators using einstein norm operations," Journal of Multiple-Valued Logic and Soft Computing, vol. 31, pp. 175-209, 2018.

[3] H. Garg, "Generalized interaction aggregation operators in intuitionistic fuzzy multiplicative preference environment 
and their application to multicriteria decision-making," $A p$ plied Intelligence, vol. 48, no. 8, pp. 2120-2136, 2018.

[4] Y. Huang, R. Lin, and X. Chen, "An enhancement EDAS method based on prospect theory," Technological and Economic Development of Economy, vol. 27, no. 5, pp. 1019-1038, 2021.

[5] G. Wei, C. Wei, J. Wu, and Y. Guo, "Probabilistic linguistic multiple attribute group decision making for location planning of electric vehicle charging stations based on the generalized dice similarity measures," Artificial Intelligence Review, vol. 54, no. 6, pp. 4137-4167, 2021.

[6] K. T. Atanassov, "More on intuitionistic fuzzy sets," Fuzzy Sets and Systems, vol. 33, no. 1, pp. 37-45, 1989.

[7] G.-F. Yu, D.-F. Li, J.-M. Qiu, and Y.-F. Ye, "Application of satisfactory degree to interval-valued intuitionistic fuzzy multi-attribute decision making," Journal of Intelligent and Fuzzy Systems, vol. 32, no. 1, pp. 1019-1028, 2017.

[8] J. Lu, S. Zhang, J. Wu, and Y. Wei, "COPRAS method for multiple attribute group decision making under picture fuzzy environment and their application to green supplier selection," Technological and Economic Development of Economy, vol. 27, no. 2, pp. 369-385, 2021.

[9] S.-P. Wan and D.-F. Li, “Atanassov's intuitionistic fuzzy programming method for heterogeneous multiattribute group decision making with Atanassov's intuitionistic fuzzy truth degrees," IEEE Transactions on Fuzzy Systems, vol. 22, no. 2, pp. 300-312, 2014.

[10] G. Wei, J. Wu, Y. Guo, J. Wang, and C. Wei, "An extended COPRAS model for multiple attribute group decision making based on single-valued neutrosophic 2-tuple linguistic environment," Technological and Economic Development of Economy, vol. 27, no. 2, pp. 353-368, 2021.

[11] Z.-X. Su, M.-Y. Chen, G.-P. Xia, and L. Wang, “An interactive method for dynamic intuitionistic fuzzy multi-attribute group decision making," Expert Systems with Applications, vol. 38, no. 12, pp. 15286-15295, 2011.

[12] A. Arya and S. P. Yadav, "Development of intuitionistic fuzzy super-efficiency slack based measure with an application to health sector," Computers \& Industrial Engineering, vol. 115, pp. 368-380, 2018.

[13] F. Tian, S. Liu, Z. Xu, and Q. Lei, "Partial derivative and complete differential of binary intuitionistic fuzzy functions," International Journal of Fuzzy Systems, vol. 19, no. 2, pp. 273-284, 2017.

[14] H. Garg, "An improved cosine similarity measure for intuitionistic fuzzy sets and their applications to decision-making process," Hacettepe Journal of Mathematics and Statistics, vol. 47, pp. 1578-1594, 2018.

[15] C. Tan, "A multi-criteria interval-valued intuitionistic fuzzy group decision making with Choquet integral-based TOPSIS," Expert Systems with Applications, vol. 38, no. 4, pp. 3023-3033, 2011.

[16] X. Zhao, Y. Zheng, and Z. Wan, "Interactive intuitionistic fuzzy methods for multilevel programming problems," Expert Systems with Applications, vol. 72, pp. 258-268, 2017.

[17] D.-F. Li, "The GOWA operator based approach to multiattribute decision making using intuitionistic fuzzy sets," Mathematical and Computer Modelling, vol. 53, no. 5-6, pp. 1182-1196, 2011.

[18] G. Büyüközkan, O. Feyzioğlu, and F. Göçer, "Selection of sustainable urban transportation alternatives using an integrated intuitionistic fuzzy Choquet integral approach," Transportation Research Part D: Transport and Environment, vol. 58, pp. 186-207, 2018.
[19] R. Joshi, S. Kumar, D. Gupta, and H. Kaur, “A Jensen- $\alpha$-norm dissimilarity measure for intuitionistic fuzzy sets and its applications in multiple attribute decision making," International Journal of Fuzzy Systems, vol. 20, no. 4, pp. 11881202, 2018.

[20] S. K. De and S. S. Sana, "The $(p, q, r, l)$ model for stochastic demand under Intuitionistic fuzzy aggregation with Bonferroni mean," Journal of Intelligent Manufacturing, vol. 29, pp. 1753-1771, 2018.

[21] J.-Q. Li, W. Chen, Z.-L. Yang, and C.-Y. Li, "A time-preference and VIKOR-based dynamic intuitionistic fuzzy decision making method," Filomat, vol. 32, no. 5, pp. 1523-1533, 2018.

[22] S. Niroomand, "A multi-objective based direct solution approach for linear programming with intuitionistic fuzzy parameters," Journal of Intelligent and Fuzzy Systems, vol. 35, no. 2, pp. 1923-1934, 2018.

[23] M. Zhao, G. Wei, C. Wei, and J. Wu, "Improved TODIM method for intuitionistic fuzzy MAGDM based on cumulative prospect theory and its application on stock investment selection," International Journal of Machine Learning and Cybernetics, vol. 12, no. 3, pp. 891-901, 2021.

[24] S. Yu, Z.-S. Xu, and S.-S. Liu, "Derivatives and differentials for multiplicative intuitionistic fuzzy information," Applied Mathematics-A Journal of Chinese Universities, vol. 32, no. 4, pp. 443-461, 2017.

[25] D. Yu, "Group decision making based on generalized intuitionistic fuzzy prioritized geometric operator," International Journal of Intelligent Systems, vol. 27, no. 7, pp. 635-661, 2012.

[26] J.-Z. Wu and Q. Zhang, "Multicriteria decision making method based on intuitionistic fuzzy weighted entropy," Expert Systems with Applications, vol. 38, no. 1, pp. 916-922, 2011.

[27] R. Verma and B. D. Sharma, "A new measure of inaccuracy with its application to multi-criteria decision making under intuitionistic fuzzy environment," Journal of Intelligent and Fuzzy Systems, vol. 27, no. 4, pp. 1811-1824, 2014.

[28] D. K. Iakovidis and E. Papageorgiou, "Intuitionistic fuzzy cognitive maps for medical decision making," IEEE Transactions on Information Technology in Biomedicine, vol. 15, no. 1, pp. 100-107, 2011.

[29] S. Zhang, H. Gao, G. Wei, and X. Chen, "Grey relational analysis method based on cumulative prospect theory for intuitionistic fuzzy multi-attribute group decision making," Journal of Intelligent and Fuzzy Systems, vol. 41, no. 2, pp. 3783-3795, 2021.

[30] M. Zhao, G. Wei, X. Chen, and Y. Wei, "Intuitionistic fuzzy MABAC method based on cumulative prospect theory for multiple attribute group decision making," International Journal of Intelligent Systems, vol. 36, no. 11, pp. 6337-6359, 2021.

[31] A. Alireza and E. Nima, "Sensitivity analysis in the QUALIFLEX and VIKOR methods," Journal of Optimization in Industrial Engineering (OIE), vol. 10, pp. 29-34, 2012.

[32] A. Amini and A. Alinezhad, "A combined evaluation method to rank alternatives based on VIKOR and DEA with BELIEF structure under uncertainty," Iranian Journal of Optimization (IJO), vol. 8, no. 2, pp. 1048-1065, 2016.

[33] S. Opricovic and G. H. Tzeng, "Extended VIKOR method in comparison with outranking methods," European Journal of Operational Research, vol. 178, no. 6, pp. 514-529, 2007.

[34] S. Opricovic and G. H. Tzeng, "Multicriteria planning of postearthquake sustainable reconstruction," Computer-Aided Civil and Infrastructure Engineering, vol. 17, no. 3, 2002. 
[35] D. Pamucar, I. Badi, K. Sanja, and R. Obradovic, "A novel approach for the selection of power-generation technology using a linguistic neutrosophic CODAS method: a case study in Libya," Energies, vol. 11, 2018.

[36] J. Roy, S. Das, S. Kar, and D. Pamucar, "An extension of the CODAS approach using interval-valued intuitionistic fuzzy set for sustainable material selection in construction projects with incomplete weight information," Symmetry-Basel, vol. 11, 2019.

[37] J. Lan, J. Wu, Y. Guo, C. Wei, G. Wei, and H. Gao, "CODAS methods for multiple attribute group decision making with interval-valued bipolar uncertain linguistic information and their application to risk assessment of Chinese enterprises' overseas mergers and acquisitions," Economic ResearchEkonomska Istraživanja, 2021, in Press.

[38] C. Wei, J. Wu, Y. Guo, and G. Wei, "Green supplier selection based on CODAS method in probabilistic uncertain linguistic environment," Technological and Economic Development of Economy, vol. 27, no. 3, pp. 530-549, 2021.

[39] T. He, S. Zhang, G. Wei, R. Wang, J. Wu, and C. Wei, "CODAS method for 2-tuple linguistic pythagorean fuzzy multiple attribute group decision making and its application to financial management performance assessment," Technological and Economic Development of Economy, vol. 26, no. 4, pp. 920-932, 2020.

[40] F. Lei, G. Wei, and X. Chen, "Model-based evaluation for online shopping platform with probabilistic double hierarchy linguistic CODAS method," International Journal of Intelligent Systems, vol. 36, no. 9, pp. 5339-5358, 2021.

[41] K. T. Atanassov, "Intuitionistic fuzzy sets," Fuzzy Sets and Systems, vol. 20, no. 1, pp. 87-96, 1986.

[42] V. Torra, "Hesitant fuzzy sets," International Journal of Intelligent Systems, vol. 25, pp. 529-539, 2010.

[43] K. Atanassov and G. Gargov, "Interval valued intuitionistic fuzzy sets," Fuzzy Sets and Systems, vol. 31, no. 3, pp. 343-349, 1989.

[44] S. Opricovic and G.-H. Tzeng, "Compromise solution by MCDM methods: a comparative analysis of VIKOR and TOPSIS," European Journal of Operational Research, vol. 156, no. 2, pp. 445-455, 2004.

[45] R. Krishankumar, K. S. Ravichandran, P. D. Liu, S. Kar, and A. H. Gandomi, "A decision framework under probabilistic hesitant fuzzy environment with probability estimation for multi-criteria decision making," Neural Computing \& Applications, vol. 33, pp. 8417-8433, 2021.

[46] Z. Xu and W. Zhou, "Consensus building with a group of decision makers under the hesitant probabilistic fuzzy environment," Fuzzy Optimization and Decision Making, vol. 16, no. 4, pp. 481-503, 2017.

[47] J. Li, Q. Chen, L.-L. Niu, and Z.-X. Wang, “An ORESTE approach for multi-criteria decision-making with probabilistic hesitant fuzzy information," International Journal of Machine Learning and Cybernetics, vol. 11, no. 7, pp. 15911609, 2020.

[48] X. Sha, C. Yin, Z. Xu, and S. Zhang, "Probabilistic hesitant fuzzy TOPSIS emergency decision-making method based on the cumulative prospect theory," Journal of Intelligent and Fuzzy Systems, vol. 40, no. 3, pp. 4367-4383, 2021.

[49] N. Liao, G. Wei, and X. Chen, "TODIM method based on cumulative prospect theory for multiple attributes group decision making under probabilistic hesitant fuzzy setting," International Journal of Fuzzy Systems, 2021, in Press.

[50] H. Liao, R. Qin, C. Gao, X. Wu, A. Hafezalkotob, and F. Herrera, "Score-HeDLiSF: a score function of hesitant fuzzy linguistic term set based on hesitant degrees and linguistic scale functions: an application to unbalanced hesitant fuzzy linguistic MULTIMOORA," Information Fusion, vol. 48, pp. 39-54, 2019.

[51] G. Wei, C. Wei, and Y. Guo, "EDAS method for probabilistic linguistic multiple attribute group decision making and their application to green supplier selection," Soft Computing, vol. 25, no. 14, pp. 9045-9053, 2021.

[52] X. Wu, H. Liao, Z. Xu, A. Hafezalkotob, and F. Herrera, "Probabilistic linguistic multimoora: a multicriteria decision making method based on the probabilistic linguistic expectation function and the improved borda rule," IEEE Transactions on Fuzzy Systems, vol. 26, no. 6, pp. 3688-3702, 2018. 